\title{
Vivendo o risco de enchentes: relatos de moradores de Campo Grande/MS
}

\author{
Dalila Castelliano de Vasconcelos - Universidade Federal do Rio Grande do Norte, Natal, Rio Grande do Norte, Brasil \\ Angela Elizabeth Lapa Coêlho - Centro Universitário de João Pessoa, João Pessoa, Paraíba, Brasil
}

\begin{abstract}
$\overline{\text { Resumo }}$
As enchentes vêm desabrigando e causando a morte de famílias no Brasil. O objetivo desta pesquisa foi identificar as vivências de pessoas que moraram durante muitos anos em uma área de risco, à beira de um córrego em Campo GrandeMS. Este estudo é inovador por abordar tal vivência como um fenômeno psicossocial. Foram realizadas entrevistas estruturadas com 19 idosos, discutidas a partir da análise de conteúdo. Para os moradores, o principal problema relativo à habitação eram as enchentes, por si só, sem atrelá-las a uma conjuntura mais ampla de risco ambiental. Por isso, perceber tal localidade como área de risco era de difícil compreensão. Faz-se necessário realizar estudos que contemplem a relação pessoa-ambiente, em uma perspectiva psicossocial, considerando que as pessoas utilizam aspectos subjetivos para compreensão de risco. Processos que envolvam essa perspectiva poderão colaborar na promoção da saúde aliada a conscientização ambiental.

Palavras-chave: Psicossocial, Área de risco, Saúde.
\end{abstract}

Living under flood risk: reports of Campo Grande/MS residents

\begin{abstract}
Floods displace and kill families in Brazil. The objective of this study was to identify the routine of living for many years on the edge of a stream in Campo Grande-MS. It is innovative because it addresses the experience as a psychosocial phenomenon. Structured interviews were conducted with 19 elderly people and they were discussed within content analysis perspective. For the participants, the main problem related to their houses was the flooding in itself without analyzing other factors related to environmental risk. So, it was difficult to perceive their neighborhood as a risk area. Thus, it is necessary to conduct studies that address the relationship between person and environment, from a psychosocial perspective, considering that people use subjective aspects to understand risk. Processes that involve this perspective could help promote health associated with environmental aw areness.

Keywords: Psychosocial, Risk area, Health.
\end{abstract}

Viviendo el riesgo de inundaciones: relatos de moradores de Campo Grande/MS

\begin{abstract}
Resumen
Las inundaciones vienen desplazando y causando la muerte de familias en Brasil. El objetivo de esta investigación fue identificar las experiencias de personas que vivieron durante muchos años en un área de riesgo, en el borde de un arroyo en Campo Grande-MS-Brasil. Este estudio es innovador al abordar esa experiencia como un fenómeno psicosocial. Fueron Se realizaron entrevistas estructuradas con 19 ancianos, discutidas a partir del análisis de contenido. Para los residentes, el principal problema en relación a las viviendas eran las inundaciones, por sí solas, sin relacionarlas a una coyuntura más amplia de riesgo ambiental. Por eso, percibir tal localidad como área de riesgo era de difícil comprensión. Es necesario realizar estudios teniendo en cuenta la relación persona-ambiente, en una perspectiva psicosocial, considerando que las personas utilizan aspectos subjetivos para comprensión de riesgo. Procesos que involucren esa perspectiva podrán colaborar en la promoción de la salud junto con la concientización ambiental.

Palabras clave: Psicosocial, Área de riesgo, Salud.
\end{abstract}

A presente pesquisa buscou conhecer quem são e como vivem as pessoas que moram à beira de córregos. De acordo com uma busca realizada no banco de dados do Scielo, em fevereiro de 2011, com o descritor enchente, apenas um resultado foi encontrado (D'Aquino, Pereira Filho \& Schettini, 2010), e com a palavra enchentes, apenas dois, um relacionado a um estudo geográfico do Rio Uruguai em 2010 (Righi \& Robaiana, 2010) e outro intitulado "A percepção do caos urbano, as enchentes e as suas repercussões nas políticas públicas da Região Metropolitana de São Paulo" (Filho, Pinto \& Ribeiro, 2006). Com o descritor área de risco, nenhum trabalho foi identificado. Já com os descritores área e risco, separadamente, foram encontrados diversos trabalhos com temáticas diferentes, como doenças específicas, contaminação de solos, entre outros, relacionados a estudos geográficos, biológicos e territoriais que não abordam a temática a partir de uma perspectiva social, psicológica ou psicossocial.

O objetivo desta pesquisa foi identificar as vivências de pessoas que moraram durante muitos anos em uma área de risco, à beira de um córrego em Campo Grande-MS, e que, a partir de um Projeto Habitacional, foram transferidas para uma área urbana da cidade.

A fim de colaborar com uma lacuna de estudos que deem voz a esses moradores, o presente artigo, buscando uma visão psicossocial sobre a vivência das pessoas que moraram em uma área de risco, mais especificamente, discute os motivos que levaram esses moradores a habitarem a margem do Córrego 
Imbiussu-Serradinho descreve as condições locais dessa moradia e as vivências nessa região. Assim, reúne algumas contribuições de estudos sobre habitação, saúde e migração, que são temas que se relacionam diretamente com a experiência à margem do córrego.

\section{Revisão teórica}

O ambiente tem grande importância na identidade da pessoa, pois é ele que situa a pessoa em vários aspectos de sua vida (Moser, 2005). Os ambientes frequentados modificam-se de acordo com o estado emocional do indivíduo. Assim, em pesquisa realizada por Macedo, Oliveira, Gunter, Alves e Nóbrega (2008), com 340 idosos, estes indicaram como lugares para ir quando estão felizes os de integração social e a casa, e quando estão tristes, a casa.

Nesse contexto, a habitação assume sua importância no processo identitário, pois se configura como um espaço de consolidação do desenvolvimento social e construção da saúde (Cohen, Cynamon, Kligerman \& Assumpção, 2004). Pinheiro, Viacara, Travassos e Brito (2002) afirmam que o local de moradia interfere não apenas no acesso aos serviços de saúde, mas, também, na compreensão do que é saúde.

O ano de 1988 apresentou muitos avanços na situação de habitação no Brasil, pois ocorreu um marco no entendimento da relação da saúde com o ambiente, com a criação do Sistema Único de Saúde (SUS) e da atual Constituição Federal (Cohen e colaboradores, 2004). De acordo com a definição de saúde da $8^{\circ}$ Conferência Nacional de Saúde (Brasil, 1986, p. 12):

Em seu sentido mais abrangente, a saúde é a resultante das condições de alimentação, habitação, educação, renda, meio ambiente, trabalho, transporte, emprego, lazer, liberdade, acesso e posse da terra e acesso a servicos de saúde. É, assim, antes de tudo, o resultado das formas de organização social da produção, as quais podem gerar grandes desigualdades nos niveis de vida.

Por outro lado, para Souza e Zioni (2003), a degradação ambiental, com seus consequentes agravos para a saúde da população, foi marcadamente influenciada pelos acontecimentos do século XIX. Tal momento foi caracterizado pela elevada concentração de populações em áreas restritas e por um padrão de desenvolvimento urbano, o que desencadeou a institucionalização de algumas práticas de apropriação de espaço e dos recursos naturais.

Jacobi (2000) realizou uma pesquisa sobre os problemas ambientais e domiciliares na cidade de São Paulo. De acordo com os resultados, uma mesma região periférica pode vivenciar, concomitantemente, diferentes problemas, pois uma família afetada pelos problemas provenientes de morar ao lado de várzeas, também pode ser afetada pelo fato de morar próxima a córregos, que, por sua vez, pode ser vítima de enchentes. Para o autor, esses fatores refletem diferentes condições socioambientais e diferenças quanto à percepção e atitudes dos moradores em relação aos problemas ambientais enfrentados.

Kran e Ferreira (2006), com base em uma análise da habitação e seu entorno, discutiram a qualidade de vida na cidade de Palmas - TO e concluíram que a qualidade de indicadores como densidade demográfica, densidade habitacional, habitações precárias, instalação sanitária, entre outros, está fortemente relacionada à forma de ocupação urbana da cidade. O que esta presencia é um processo de urbanização excludente, que faz com que a população mais carente busque formas alternativas, como invasões de prédios e terrenos e ligações clandestinas. Tal prática é legitimada pela legislação de ocupação e uso do solo urbano e pela especulação imobiliária.

Diante desse tipo de situação, Genevois e Costa (2001) defendem que, para ocorrer o aprimoramento dos dados sobre déficits habitacionais, deve-se identificar os domicílios pela forma de ocupação, características do espaço e pelas características da habitação, considerando sempre a cidade "real", que inclui os chamados "moradores de rua", "invasores", os contratos verbais de aluguel, ocupações de construções inacabadas, entre outros. Dessa forma, os autores acreditam que podem caminhar para o melhoramento das condições de vida e de moradia daquela população mais necessitada.

Souza (1998) realizou uma pesquisa especificamente com ocupantes de terra que lutavam por moradia na cidade de São Paulo, com o objetivo de analisar a reelaboração da identidade e da linguagem desses moradores. Os participantes revelaram passar por diversas situações de preconceito e discriminação. O sentimento de indignação com tal situação levou essas pessoas ao questionamento de serem realmente pessoas, por morarem em barracos, fato este que está fortemente relacionado ao processo de migração e que, para esse grupo, envolve muito trabalho, sofrimento e discriminação. Uma nova linguagem adotada por essas pessoas foi de se denominarem ocupantes e não mais invasores.

Brito e Souza (2005), ao pesquisarem o processo de urbanização e concentração da população nos grandes aglomerados metropolitanos, analisaram como esse processo ocorreu no Brasil, utilizando como referência a Região Metropolitana de Belo Horizonte. Os autores afirmam que ambos os processos ocorreram praticamente da mesma forma, tendo em comum a metropolização da pobreza. A partir disso, verifica-se o quanto as condições de habitação e o processo de migração estão relacionados com a 
economia, a ação ou a omissão do poder público e com a desigualdade social presentes no Brasil. Pode-se inferir que o processo de saturação imobiliária também pode ocorrer entre bairros de uma mesma cidade.

Em um estudo pioneiro por abordar o processo de migração interna no Brasil e seus desdobramentos na saúde em uma dimensão sociocultural, Silva e Queiroz (2006) realizaram uma pesquisa qualitativa com migrantes que se deslocaram para Campinas, São Paulo. Para se mudarem, os migrantes fazem uso de uma rede social que envolve, principalmente, os parentes que já haviam migrado, os quais oferecem suas casas e apoio precário àqueles que acabam de chegar e que apresentam incertezas quanto ao emprego. A vida social e familiar se organiza em torno do trabalho, e é o emprego que define a permanência no novo local de moradia. Cunha (2005) e Corsini (2006) também ressaltam a importância das redes de apoio familiar e social sobre o processo migratório.

Em Campo Grande, o ponto máximo da imigração, conforme Pereira (2001), ocorreu em 1977, quando a cidade passou a ser a capital do Estado de Mato Grosso do Sul. Essa corrente migratória vinda dos países vizinhos, dos estados do centro-sul e do próprio estado era atraída pelo desmatamento de enormes áreas arrendadas pelos seus proprietários. A expansão dos latifúndios possibilitou que a população assalariada fosse expulsa do campo pelo advento da mecanização, o que impulsionou a migração em massa para a cidade de Campo Grande. Tal fenômeno gerou um excedente de mão de obra. Essa população não inserida em algum programa específico para conseguir adquirir propriedades " [...] passou a viver em barracos de papelão, lonas e restos de materiais de construção, nos arredores da cidade, formando grande aglomerados de favelas, caracterizadas por invasões de terrenos ou áreas públicas próximas aos córregos" (Pereira, 2001, p. 96). De acordo com a autora, na atualidade, os migrantes são atendidos pelo Centro de Triagem e Encaminhamento ao Migrante de Campo Grande - MS (CETREMI) ou entidades não-governamentais.

Abordar a temática da migração sob a perspectiva das representações sociais (RS) permite que se transponha o entendimento de que a fala de uma pessoa seja uma construção apenas individual. As RS não são criadas por uma única pessoa. Uma vez existindo, elas ganham uma dinâmica própria, interagindo e presenciando o fim de outras RS. Para compreender uma RS, é necessário identificar a partir de quais outras RS ela emergiu, pois as RS, uma vez compartilhadas por todos e reafirmadas pela tradição, constituem uma realidade social própria (Moscovici, 2003).
Segundo Jodelet (2001, p. 22), Representações Sociais "[...] é uma forma de conhecimento, socialmente elaborada e partilhada, com um objetivo prático, e que contribui para a construção de uma realidade comum a um conjunto social." As RS são um conhecimento prático, tanto pelas circunstâncias em que são produzidas quanto pelo seu objetivo de eficácia social de agir sobre o mundo. Entre as RS, visões de mundo e as práticas sociais existe uma série de mediações, como o controle exercido por diferentes aparelhos de poder e situações novas que obrigam a população a exercer novas práticas (Andrade, 2000).

$\mathrm{Na}$ dinâmica das relações entre pessoas, fatos e objetos, está presente o processo de familiarização, que será considerado dentro de paradigmas e encontros ocorridos em um momento anterior ao evento que está sendo vivenciado. Dessa forma, a memória, o passado, a resposta e as imagens prevalecem, respectivamente, sobre a dedução, o presente, o estímulo e a realidade. Isso ocorre para que as pessoas possam ser minimamente independentes dos acontecimentos atuais, protegendo-as contra acontecimentos súbitos. As influências sociais da comunicação sustentam representações que possibilitam a construção de uma realidade comum que serve para as pessoas se ligarem umas às outras. Sendo assim, o conhecimento é sempre o produto da interação e comunicação (Moscovici, 2003).

Diversos estudos das RS envolvem questões e recursos ambientais. Polli, Kuhnen, Azevedo, Fantin e Silva (2009) utilizaram os estudos das RS para abordar os problemas relativos à água em Santa Catarina. Nesse estudo os participantes compreenderam a água como essencial à vida e relacionada à saúde e à preservação. Elementos como poluição, escassez e economia estiveram presentes, refletindo a preocupação relativa a esse recurso e à necessidade de sua preservação.

Souza e Zioni (2003), utilizando o referencial teórico das RS, buscaram identificar quais os significados que moradores de áreas de mananciais atribuem ao meio ambiente e como se apropriam de tais recursos. O rio para essas pessoas é um elemento de identidade e faz parte da paisagem do local. O meio ambiente é entendido como aquele que é natural e propicia o acesso universal à saúde.

Assim, articular os estudos das representações sociais com as temáticas enchentes, habitação, saúde, ambiente e migração pode ser de grande valia para uma melhor compreensão dessas temáticas, que estão relacionadas aos motivos e às vivências de parcelas da população brasileira que moram à margem dos rios. E, de acordo com Coêlho (2007), experiências repetidas com um mesmo evento, como, por exemplo, as enchentes, podem gerar uma sub-cultura do desastre, $\mathrm{o}$ 
que pode mitigar os efeitos do estresse, alterar o significado do evento, assim como a resposta a ele.

\section{Método}

\section{Participantes}

Participaram da pesquisa todas as pessoas que frequentavam o grupo de idosos do Centro de Referência de Apoio Social (CRAS) e que eram moradores beneficiados pelo projeto "Mudando para Melhor Imbirussu-Serradinho", desenvolvido pela Unidade Executora Municipal, coordenada pela Empresa Municipal de Habitação (EMHA). Inicialmente, essa população morava de forma irregular em áreas em torno dos córregos Imbirussu e Serradinho, estava exposta aos problemas ocasionados pelas enchentes dos mesmos e, por meio do Projeto, foram transferidas para a área urbana da região.

\section{Instrumento}

$O$ instrumento utilizado foi uma entrevista estruturada, cujo roteiro foi construído pelas pesquisadoras. A entrevista era composta de 33 itens, sendo 14 sobre dados sociodemográficos, nove sobre a mudança de local de moradia e 10 sobre o processo saúde-doença.

\section{Procedimentos}

A pesquisa foi realizada de acordo com a Resolução 196/96 do Conselho Nacional de Saúde conforme o que é preconizado para pesquisas com seres humanos, e protocolada sob o $\mathrm{n}^{\circ} 055 / 2008 \mathrm{~B}$ no Comitê de Ética em Pesquisa da Universidade Católica Dom Bosco. Inicialmente, fizemos uma visita durante uma reunião do grupo de idosos no Centro de Referência de Assistência Social (CRAS) para informar os objetivos da pesquisa. Em seguida, foi agendada, com cada pessoa que aceitou participar da pesquisa, uma entrevista individual, com hora e local previamente acordados entre a pesquisadora e $\mathrm{o}$ participante.

Durante as entrevistas individuais, foi lido e explicado o Termo de Consentimento Livre e Esclarecido (TCLE), o qual, além de descrever os objetivos da pesquisa, explicitava que o entrevistado poderia desistir a qualquer momento de participar dela, bem como deixar de responder a qualquer pergunta. Após a leitura, aqueles que aceitaram participar assinaram o TCLE, e a entrevista era iniciada. A entrevista foi gravada com o prévio consentimento do participante. As entrevistas com os participantes foram realizadas, dependendo do que ficaria mais conveniente para o participante, ou no Centro de Referência e Apoio Social (CRAS) ou em suas residências, localizados no bairro Jardim Aeroporto, na cidade de Campo Grande, MS.

Após as entrevistas, foi realizada uma análise quantitativa dos dados sociodemográficos e qualitativa dos relatos dos participantes. Os dados foram analisados a partir das contribuições teóricometodológicas da análise de conteúdo de Bardin (1994) e seguiram as seguintes etapas: 1-transcrição das entrevistas gravadas; 2- identificação de temas; 3demarcação de unidades de sentido a partir dos conteúdos; 4- construção de categorias. A fim de preservar o anonimato dos participantes, a letra "P" seguida de um número de identificação foi adotada, acrescida do sexo, identificado pela letra " $F$ " para o sexo feminino e " $M$ " para o masculino, e as idades de cada participante.

\section{Resultados e Discussão}

Participaram da pesquisa 19 moradores, sendo 16 mulheres e três homens, com idades que variaram entre 49 e 85 anos, com média de idade de 63 anos e desvio padrão 3,41. Mesmo sendo um grupo de idosos do CRAS, algumas pessoas com menos de 60 anos participam.

A maioria dos participantes vivia à beira do córrego há 20 anos e tinha baixo grau de escolaridade ou nunca havia estudado. Quanto à ocupação, a maioria afirmou realizar atividades domésticas (11 participantes), quatro não responderam, três afirmaram que já trabalharam e que atualmente recebem aposentadoria, e uma trabalha de diarista.

\section{Motivo de viver à beira do córrego}

A maioria dos participantes descreveu como motivo de morar à beira do córrego o fato de não conseguirem pagar aluguel nem comprar uma casa em outra localidade. Os participantes, ao serem questionados sobre os motivos de morarem à beira do córrego, demonstraram surpresa com tal pergunta, pois, para elas, o motivo era óbvio, como se o próprio fato de morar ali já respondesse a essa questão. $\mathrm{Ou}$ seja, trata-se de uma falta de opção. É esse tipo de vivência que parece influenciar a construção de entendimentos de que algo pode se realizar por ele mesmo, sem influência da atividade da própria pessoa no processo. Afinal, não foram as escolhas pessoais que fizeram com que essa população fosse morar naquele lugar.

Uai? Pru que num tinha outro lugar!... que eu arrumei foi aquele ali mesmo. Se tivesse outro lugar en num tinha ficava ali né?...(P5 - M, 66 anos)

Essa postura diante dos acontecimentos da vida reflete-se na forma de se relacionar com diferentes 
realidades. No estudo das RS, Andrade (2000) comenta que o sentido de uma dada RS depende muito mais da forma como seus conteúdos estão organizados do que propriamente de seus conteúdos. Assim, ao longo de outros questionamentos realizados durante a entrevista, pôde-se perceber como essa vivência de falta de escolha diante dos acontecimentos da vida perpassa outras temáticas, como o processo saúde-doença e o processo de migração. Assim, a forma que novos conteúdos são organizados parece se associar a esse entendimento.

O processo de ocupação vivenciado pelos participantes em Campo Grande assemelha-se ao que comentam Kran e Ferreira (2006), que, paralelo ao crescimento comercial e residencial e a um planejamento de ocupação e extensão da cidade, ocorreu um aumento dos núcleos carentes que são empurrados para áreas de "habitação popular" ou áreas de ocupação irregular. Dessa forma, os autores alertam para a necessidade de agilidade e flexibilidade das políticas ambientais, que parecem caminhar mais lentamente que a dinâmica da cidade. Mesmo assim, é sabido que alguns estudos e segmentos sociais tratam tal vivência como se fosse uma escolha dos moradores. É nesse sentido que Genovois e Costa (2001) defendem que a população que habita a chamada "cidade irregular" não pode ser responsabilizada por essa situação, uma vez que ela não tem acesso ao mercado imobiliário formal, e essa alternativa se apresenta como a única forma de conseguir um abrigo.

Sabe é porque nós chegô de fora né? Nós morava é, num era aqui. Aí meu cunbado que comprou de outra, lá aquele pedaço, aquele lote né? Disse que era dele, né? E num era, era da prefeitura... O pai, meu sogro já morava lá né? A gente fer uma casinha perto... pra cuidar dele... É que falaram que o terreno era da prefeitura né? E num vendia, né? Mas num foi nós que entrou assim. Pra dizerer que entrô sem saber, né? Entrou porque outros já tinham comprado o direito né? (P14 - F, 58 anos)

$\mathrm{O}$ que aqui se destaca é que alguns moradores acreditavam que tinham uma permissão do Estado para morar naquele local e/ou por uma falta de opção foram morar ali. Pode-se inferir aqui sobre a necessidade desses moradores de não serem denominados invasores, ou qualquer outra nomenclatura similar, uma vez que ela pode denotar um caráter de irresponsabilidade do morador ou ainda considerar que tal população apresenta uma postura ativa em relação à conquista de território. O que ocorre nesses casos expostos é que, por falta de escolha e de um espaço próprio para morar, essa população acaba por ter que habitar áreas ribeirinhas.
Tal processo apresenta grande importância na construção da identidade dessas pessoas, pois, segundo Corsini (2006), muito do que a pessoa compreende como parte de sua identidade se relaciona à forma como ela entende que é percebida pelo outro. Ou seja, o desconforto causado pelo entendimento que os outros apresentam em relação a essa população ribeirinha, considerando-a como invasores, interfere na construção da identidade desses moradores.

Para Souza (1998), a rotulação de "invasores" acaba por desqualificar a condição de pessoa e limita o direito de cidadania. De acordo com Jodelet (2001), o compartilhar de uma mesma RS com outros ocorre ora de maneira convergente, quando se tem apoio; ora divergente, quando ocorrem conflitos. As representações sociais, segundo a autora, ao fazer parte do cotidiano das pessoas, ajudam-nas a identificar, interpretar, decidir e, por vezes, a se posicionar a respeito de diferentes aspectos da realidade. Nesse caso, ao se apropriarem de sua realidade, esses moradores já não aceitam mais a nomeação que outros grupos sociais lhes atribuem, porém, não criam ainda sua própria linguagem. Isso indica que não ocorreu o processo de ancoragem desse novo entendimento, que, para Moscovici (2003), é o processo pelo qual se nomeiam e classificam os objetos e as ideias.

Outros movimentos migratórios e a importância das redes sociais de apoio

Durante as explicações sobre o motivo de morarem à beira do córrego, surgiram depoimentos sobre a vivência de outros movimentos migratórios por parte daqueles participantes. É o que pode ser verificado em relatos como o descrito abaixo.

O motivo? Ab foi que eu vim de fora, eu timba vendido umas coisinha meu que eu tinha tido lá pra fora, ai tinha um barraquinho lá que tava vendendo, que eu, o dinheiro não dava para comprar casa mesmo de verdade, tinha um barraquinho lá e en comprei esse barraquinho... (P3 - F, 61 anos)

Nas últimas décadas, conforme Cunha (2005), diferentes formas de migração, que vão além das questões rural-urbanas, passam a ser consideradas, em razão de sua importância política, social e econômica no contexto nacional e internacional. Essa diversidade é verificada no grupo que participou desta pesquisa, pois apenas sete participantes nasceram no estado do Mato Grosso do Sul, porém, nenhum na cidade de Campo Grande, e dentre os demais estados, ocorreu uma elevada variedade.

Essas vivências retratam o que Silva e Queiroz (2006) descrevem: que as pessoas de baixa renda ao serem atraídas pelos centros urbanos acabam por morar em locais em torno das metrópoles, que são 
áreas pouco valorizadas e com pouca infraestrutura urbana, por serem terrenos baratos e próximos ao local de trabalho. Uma vez não se tendo uma política maior de migração, soluções mais particulares são tomadas. Entretanto, quando se considera que o processo migratório trata-se de escolhas pessoais, fica limitado o desenvolvimento de construção de políticas governamentais que tratem esse fenômeno em dimensões ampliadas.

Antes eu morava em Mato Grosso né? Ai meu filho veio e tinha esse terreno... aí, meu cunbado vendeu para ele né? $\mathrm{O}$ direito né?[...] Então meu filho foi, passou a morar lá e tinha uma casinha de talbua ai meu esposo veio lá do Mato Grosso, fez assim uma meiada..., ai os menino conseguiu comprar mais material, ai ele fez as outras peça... completou a casa... Ai nós resolvemo vim...en e men esposo, que meus três filho já estava aqui... Assim, sem, mas com a ideia de voltar para lá. Mas ai depois men esposo falecen aqui ai en fiquei junto com meus filho. (P8 - F, 56 anos)

Essa realidade é comentada por Silva e Queiroz (2006), que afirmam que um tipo de estratégia utilizada pelos migrantes é a de uma rede social que envolve, principalmente, os parentes que já haviam migrado.É a respeito desse tipo de vivência que Corsini (2006) comenta sobre a autonomia das migrações, em que são as pessoas, as redes familiares e afetivas que dão formas à migração, muito mais que os governos. Dessa forma, infere-se que o nível de atuação do governo, tanto no local de origem, quanto no local de chegada do migrante, apresenta uma importante função no processo de migração.

\section{Vivendo à margem e à mercê do córrego}

Os participantes, durante a entrevista, foram solicitados a comentar sobre seu antigo local de moradia. Tal localidade foi representada como um lugar sem nome e de difícil acesso, o que torna complicado delimitá-lo em um bairro. Tal lugar, por vezes, pode ser compreendido como sendo à margem da lei e da dignidade humana.

Era lá na beira do córrego. Sabe lá em baixo. $\mathrm{Na}$ beira do córrego. Lá que era. Na Saionara, parece que é Saionara. Num sei, é Saionara.... (P13 - F, 76 anos)

Primeiramente, é importante que se esteja atento ao que comenta Moser (2005) sobre o ambiente apresentar grande importância na identidade da pessoa, pois é o ambiente que situa a pessoa em vários aspectos de sua vida, sejam eles sociais, econômicos ou culturais. Diante da importância de se garantir dignidade humana para todos é que Cohen e colaboradores (2004) afirmam ser necessário que se apresentem requisitos mínimos de moradia que propiciem saúde e bem-estar.

Souza (1998), em sua pesquisa com ocupantes de terra, afirma que essas pessoas passam por diversas situações de preconceito e discriminação, pelo fato de não pertencerem ao modelo socialmente vigente. $\mathrm{E}$ acrescenta que essa mesma sociedade não questiona $\mathrm{O}$ motivo de tal situação.

Essa sociedade colabora e oferece subsídios para a construção de RS desses moradores como pessoas que não devem ser aceitas na sociedade. Afinal, a RS que a sociedade tem desses moradores parece interferir na forma como eles se percebem. Aqui aparece o que comenta Jodelet (2001), de quando uma dada RS atravessa as pessoas, por ser imposta pela ideologia dominante ou pela estrutura social. Morar à beira do córrego os deixa expostos a diferentes riscos ambientais e torna o acesso a recursos e serviços mais difícil.

Lá num, os pobrema maior mermo era da enchente. Quando era tempo de chuva. Ai, e também não tinha tanto curso né? Que aqui tá havendo mais oportunidade, curso para todos que se interessarem fazer... (P11 - F, 63 anos)

Evidencia-se, aqui, o comentário de Jacobi (2000) de que as diferenças territoriais provocam diferentes riscos ambientais, como, também, propiciam uma diferença no acesso a determinados serviços.

Lá num tinha o que tem aqui agora. Lá não tinha. Não tinha nada dessas coisa de diversão. A gente era muito fechada né?....(P16 - F, 54 anos)

Essa realidade vai ao encontro do que comentam Souza e Zioni (2003), que, nas periferias das cidades, as populações de baixo nível socioeconômico vivenciam diversas carências, como escassez de moradia, saneamento, saúde, lazer, entre outros. Esse quadro socioambiental relativo à moradia se torna particularmente mais importante quando considerada a população idosa, pois, segundo Macedo e colaboradores (2008), a casa, independente do estado emocional dos idosos, é o lugar preferido por eles. Assim, podemos inferir que tal grupo etário provavelmente se torne mais vulnerável, uma vez que apresenta grande apego à casa. A falta de acesso a esses bens e serviços, dentre eles os de saúde, gera mais isolamento social.

Ih, lá tinha pobrema de, é, eu não podia consultar, num era fácil pra mim consulta...(P17 - F, 59 anos)

Os probrema é a água e num pudê saí, aí ficava tudo preso... (P12 - F, 62 anos)

Pinheiro e colaboradores (2002) comentam que as barreiras no acesso aos serviços de saúde estão relacionadas à oferta de serviços. A esse fator acrescentam-se as dificuldades provenientes de 
condições físicas do ambiente em que as pessoas residem, sendo necessário, então, não apenas considerar a área onde residem, mas, também, o local dentro dessa área. O que aqui precisa ser destacado é que o cuidado com a saúde, relativo à ida até uma instituição de saúde, é apenas mais um serviço a que essas pessoas não têm acesso, principalmente, nos períodos de enchente, pois o acesso a outros serviços que interferem no cuidado com a saúde, como, por exemplo, ir à escola ou participar de atividades sociais, também fica diretamente afetado.

Dois fatores relacionados ao local de moradia se associam diretamente na forma dessa população cuidar de sua saúde. O primeiro são as condições de saúde propiciadas pelo próprio ambiente em que vivem, e o outro é a dificuldade de acesso aos serviços que propiciam o cuidado com a mesma. A isso ainda se soma o fato de a população que participou da pesquisa ser idosa, pois, como comentam Macedo e colaboradores (2008), em tal idade, por vezes, se apresentam perdas físicas e de mobilidade, o que torna o acesso a outros ambientes, externos a casa, mais difícil. Percebe-se, assim, a limitação enfrentada por essa população no cuidado com a saúde, pois, ao mesmo tempo em que não contam com boas condições habitacionais, também apresentam um acesso limitado aos serviços sociais e de saúde.

O maior problema de morar à beira do córrego, destacado pelos participantes, era o da enchente. Isso pode ser verificado nos relatos abaixo.

Quando enchia o córrego a água tomava conta de nossas casa. Era rato, cobra, tudo, e ia tudo pra dentro de casa. Era horrive... (P3 - F, 61 anos)

A água entrava na porta da, da sala e saia na porta da cozinha... Se nós num saísse de lá morria, morria afogado. Ou então derrubava a parede em cima de nós... Tinha nem acabado de se a parede já caiu. Se nós tivesse lá tinha caído em cima. Meu pai do céu. Num quero mais lembrar daquilo lá mais não! (P5 M, 66 anos)

Muitos participantes relataram morar dentro da água e dentro de um brejo, e comentaram sobre a presença de mosquitos e a alta umidade do local. Essas falas vinham seguidas de comentários como "... Era muito ruim", "lá era ruim, né?" etc. Isso representava a grande carga afetiva da representação social desse local para o grupo, pois, como afirma Jodelet (2001), a comunicação, que é um elemento fundamental da RS, apresenta aspectos emocionais que propiciam a liberação de sentimentos provenientes de crises e conflitos.

Quando se trabalha com o conceito ampliado de saúde, há a compreensão de que isso se trata de um problema de saúde pública, uma vez que o objetivo final de um profissional de saúde é a promoção e a proteção do bem-estar da população. Cohen e colaboradores (2004) comentam dessa relação entre a precariedade habitacional e a saúde das pessoas que habitam ambientes insalubres, e alerta para uma maior aproximação da comunidade científica com essa realidade e para a necessidade de aumentar a qualidade das políticas públicas de saúde. Para os autores, apenas podem existir cidades e municípios saudáveis quando estes tiverem habitações saudáveis.

Ressalta-se aqui a importância do contexto e das vivências na construção das RS, pois, durante as entrevistas, a água foi entendida como aquela que invade, degrada, causa medo, diferenciando-se das RS da água encontradas por Polli e colaboradores (2009) em comunidades rurais de Santa Catarina, que foi representada como essencial à vida, à saúde, e que deve ser preservada. Apresenta-se uma grande complexidade entre a pessoa e esse recurso, pois a água pode ser compreendida de diversas formas quando considerada em relação a populações que foram vítimas de enchentes. Alguns participantes se referiram principalmente à última enchente que ocorreu no local, antes do início do processo de migração para a área urbana:

Por que antes de nós mudar para cá, deu uma enchente que a água veio assim. Os bombeiro, ajudando .... Todo foi socorrido a barco.(P1 - F, 61 anos)

Sempre que chovia alguém tinha que ficar cuidando, até o dia que deu essa última enchente, que levou tudo o que a gente tinha. À noite a gente dormiu no colégio, eles fizeram comida e muita roupa que arrumaram... Porque nós ficou, todo mundo... oitocentas e poucas familia. Perdeu tudo. (P1 - F, 61 anos)

$E$ ai as enchente, em casa nunca tinha entrado, mas o último ano que nós mudou, entrou também na nossa casa, né? Então a gente ficou correndo o risco de, como fala? De vida, né? Porque na beira do rio, né? (P14 $\mathrm{F}, 58$ anos)

Lá problema era negócio da enchente só né? Porque você num... num ficava tranquila porque... quando virava o tempo você não sabia se ocê dormia on ficava cuidando o tempo.... E ainda bem que aquela vez que deu aquela enchente, deu de dia né, porque se fosse à noite nós ia morrer tudo afogado... porque pegou todo mundo de surpresa, porque ninguém sabia. (P4 - F, 65 anos)

Se en tivesse lá en ... sei lá se eu num tivesse morrido afogado. (P5 - M, 66 anos)

Mesmo com a última enchente, algumas casas não foram inundadas. $\mathrm{O}$ fato de nunca ter entrado água em casa aumenta a resistência de se mudar e o sentimento de ser prejudicado com a mudança, o que dificulta a compreensão dos moradores que lá residiam de que tal 
área fosse imprópria para morar. Essa compreensão vai do encontro do que Coêlho (2007) comenta, que as pessoas, ao invés de fazerem uso de uma medida objetiva do perigo, baseiam-se em uma visão pessoal do risco. Ainda, segundo a autora, o entendimento de que uma determinada área é de risco depende de uma complexa interação entre a pessoa e o evento, como pode ser verificado no relato a seguir:

Eu morava... Uma área não de risco. Eu vim mesmo porque... a prefeitura ia ocupar o nosso lugar. Eu vivi... deaoito ano lá. E vim pra cá e me prejudiquei muito... A minha casa era tão grande lá. Nunca entrou água...(P16 - F, 54 anos)

Problema era só mesmo era, é, é lá num, porque minha casa en aterrei, ficon muito arta. Chovia não entrava na minha casa. Nas outra casa entrava tudo, na minha que era mais alta... ele paralison aí.. e aí o córrego num enchia até em cima. Até minha casa nunca encheu. E o prefeito tirou todo mundo da beira do córrego por causa da enchente...(P6 - M, 86 anos).

Ter que abandonar uma casa que nunca havia sido inundada torna o processo de desocupação ainda mais doloroso, pois dificulta a compreensão de que o local onde uma dada casa foi construída trata-se de uma área de risco. Por esse motivo, quando da remoção dessas populações, as equipes responsáveis pela realização da migração devem entender e considerar a compreensão dos participantes sobre o que seja uma área de risco e as relações afetivas que os moradores têm em relação a sua habitação.

De acordo com Coêlho (2007), ao se elaborarem estratégias que incluam a questão do risco, deve-se considerar que, juntamente aos resultados das análises técnicas sobre o risco, deve-se incluir a percepção subjetiva das pessoas envolvidas nesse processo. Assim, quando da necessidade de remanejamento de populações expostas a riscos, como é o caso da população que participou da presente pesquisa em relação às enchentes, é necessário compreender e considerar, antes da realização do processo migratório, a compreensão dos mesmos sobre o que é uma área de risco.

\section{Considerações finais}

De acordo com o objetivo geral proposto para esta pesquisa, consideramos que os dados apresentados revelam que a proposta foi atingida. No entanto, sugerimos que esta pesquisa possa ser ampliada em outras regiões do país com características diferentes, bem como com outras faixas etárias. Também seria interessante estudos que buscassem compreender o motivo de determinadas populações receberem moradias em locais considerados seguros pelos órgãos governamentais e retornarem após algum tempo para seus antigos locais de moradia, mesmo sendo uma área de risco.

Morar à beira do córrego, longe de ser uma situação desejada pelos moradores, é fruto de uma relação de problemas sociais e econômicos que apresentam reflexos nas condições de saúde. Nesse caso analisado, as enchentes impossibilitavam que os moradores tivessem acesso a serviços básicos de saúde e de assistência social. Além dos riscos à exposição a doenças provenientes de residirem numa área imprópria para moradia, que não conta com sistema de saneamento e infraestrutura adequada, as enchentes os expõem mais diretamente ao contato com lixo, animais em decomposição, entre outros. Somam-se a estes o risco de desabamento, que pode provocar a morte dos moradores por soterramento ou afogamento.

Embora reconheçam diversos problemas pertinentes à localidade, o fator motivador para uma mudança, de acordo com o relato dos participantes, era o risco de vida que os mesmos corriam. Podemos inferir que é o risco eminente da vida que pode contribuir mais diretamente para a percepção de que se trata de uma área de risco.

Tratar a temática da vivência das enchentes com idosos parece ser de grande valia, uma vez que esses, por conta de limitações físicas, são mais diretamente afetados pelas condições espaciais inadequadas à mobilidade. A utilização da Teoria das Representações Sociais foi satisfatória para o presente estudo, pois possibilitou uma visão ampliada do processo vivenciado por essa população.

Desse modo, os projetos de remanejamento devem considerar a percepção de risco como uma questão que envolve a subjetividade e as vivências pessoais. A compreensão do processo saúde-doença por parte dos moradores parece ser um campo que pode ser explorado nesse processo. $\mathrm{O}$ investimento em políticas habitacionais pelas agências governamentais também se configura como um aspecto importante para a minimização dessa problemática. Agindo preventivamente, podemos reduzir o número de desabrigados e falecidos, bem como os agravos psicossociais dos sobreviventes. Essa ação preventiva também repercutirá na esfera governamental, tendo em vista os gastos com ações pós-evento provenientes das enchentes, como alojamentos temporários em escolas, galpões, entre outros, além de prevenir doenças e problemas provenientes da falta de acesso a diferentes serviços sociais, de saúde e educacionais. 


\section{Referências}

Andrade, M. A. A. de. (2000). A identidade como representação e a representação da identidade. Em A. S. P. Moreira \& D. C. de Oliveira (Orgs.). Estudos interdisciplinares de representação social (pp. 141-149). $2^{\mathrm{a}}$ ed. Goiânia: AB.

Bardin, L. (1994). Análise de conteúdo. Lisboa: Edições 69.

Brasil. (1986). Relatório da VIII Conferência Nacional de Saúde. Obtido em: www.conselho.saude.gov.br/biblioteca/Relatorios / relatorio. Acesso em: 9 fev. 2012.

Brito, F. \& Souza, J. de. (2005). Expansão urbana nas grandes metrópoles: o significado das migrações intrametropolitanas e da mobilidade pendular na reprodução da pobreza. São Paulo em Perspectiva, 19(4), 48-63.

Coêlho, A. E. L. (2007). Percepção de risco no contexto da seca: um estudo exploratório. Psicología para a América Latina, 10. Obtido em: www.psicolatina.org/10/risco.html. Acesso em: 9 fev. 2012

Cohen, S. C., Cynamon, S. E., Kligerman D. C. \& Assumpção, R. F. (2004). Habitação saudável no Programa Saúde da Família (PSF): uma estratégia para as políticas públicas de saúde e ambiente. Ciência \& Saúde Coletiva, 9(3), 807-813.

Corsini, L. (2006) Repensando a identidade no contexto das migrações. Psicologia e Sociedade, 18(3), 23-33.

Cunha, J. M. P. da. (2005). Migração e urbanização no Brasil: alguns desafios metodológicos para análise. São Paulo em Perspectiva, 19(4), 3-20.

D'Aquino, C. de A., Pereira Filho, J. \& Schettini, C. A. F. (2010). Fluvial modulation of hydrodynamics and salt transport in a highly stratified estuary. Brazilian Journal of Oceanography, 58(2), 165-175.

Filho, A., Pinto, A. \& Ribeiro, H. (2006). A percepção do caos urbano, as enchentes $\mathrm{e}$ as suas repercussões nas políticas públicas da Região Metropolitana de São Paulo. Saúde e Sociedade, 15(3), 145-161.

Genevois, M. L. B. P. \& Costa, O. V. (2001). Carência habitacional e déficit de moradias: questões metodológicas. São Paulo em Perspectiva, 15(1), 7384.

Jacobi, P. (2000). Do centro à periferia - meio ambiente e cotidiano na cidade de São Paulo. Ambiente \& Sociedade, Ano 3 (6/7), 145-162.
Jodelet, D. (2001). Representações sociais: um domínio em expansão. Em D. Jodelet (Org.). As representações sociais (pp. 17-44). Rio de Janeiro: EDURJ.

Kran, F. \& Ferreira, F. P. M. (2006). Qualidade de vida na cidade de Palmas-TO: uma análise através de indicadores habitacionais e ambientais urbanos. Ambiente \& Sociedade, 9(2), 123-141.

Macedo, D., Oliveira, C. V., Günter, I de A., Alves, S. M. \& Nóbrega, T. S.(2008). O lugar do afeto, o afeto pelo lugar: o que dizem os idosos? Psicologia: Teoria e pesquisa, 24(4), 441-449.

Moscovici, S. (2003). Representaçôes sociais: investigaçoes em psicologia social. Petrópolis: Vozes.

Moser, G. (2005). A psicologia ambiental: competência e contornos de uma disciplina. Comentários a partir das contribuições. Psicologia USP, 16(1-2), 279-294.

Pereira, E. C. C. (2001). O perfil do migrante que busca a cidade de Campo Grande-MS (Dissertação de Mestrado). Franca: Universidade Estadual Paulista "Julio de Mesquita Filho", Faculdade de História, Direito e Serviço Social.

Pinheiro, R. S., Viacara, F., Travassos, C. \& Brito, A. dos S. (2002). Gênero, morbidade, acesso e utilização de serviços de saúde no Brasil. Ciência \& Saúde Coletiva, 7(4), 687-707.

Polli, G. M., Kuhnen, A., Azevedo, E. G. de, Fantin, J. \& Silva, R. F. G. da. (2009). Representações Sociais da água em Santa Catarina, Psicologia em Estudo, 14(3), 529-536.

Righi, E. \& Robaina, L. E. de S. (2010). Enchentes do Rio Uruguai no Rio Grande do Sul entre 1980 e 2005: uma análise geográfica. Sociedade e Natureza, 22(1), 35-54.

Silva, M. A. de M. \& Queiroz, M. de S. (2006). Somatização em migrantes de baixa renda no Brasil. Psicologia e Sociedade, 18(1), 31-39.

Souza, D. V. de \& Zioni, F. (2003). Novas perspectivas de análise em investigações sobre o meio ambiente: a teoria das representações sociais e a técnica qualitativa da triangulação de dados. Saúde e Sociedade, 12(2), 76-85.

Souza, J. C. de. (1998). Ocupações de áreas urbanas em São Paulo: Trajetórias de vida: linguagens e representações. Revista Brasileira de História, 18(35), 361-373.

Recebido em 20/06/2012

Reformulado em 05/02/2013

Aprovado em 26/03/2013 
Nota das autoras:

Agradecemos à Coordenação de Aperfeiçoamento de Pessoal de Nível Superior (CAPES) pelo apoio financeiro para esse estudo, por meio de bolsa de mestrado.

Sobre as autoras:

Dalila Castelliano de Vasconcelos é psicóloga e mestre em Psicologia da Saúde pela Universidade Católica Dom Bosco-UCDB, Campo Grande-MS e especialista em Saúde Pública e Saúde da Família e, atualmente, doutoranda em Psicologia Social da Universidade Federal da Paraíba-UFPB.

Angela Elizabeth Lapa Coêlho é psicóloga e mestre em Psicologia Social pela Universidade Federal da Paraiba, com doutorado e pós-doutorado em Psicologia pela University of Manitabo, Canadá. Atualmente, é coordenadora do curso de Psicologia do Centro Universitário de João Pessoa (UNIPÊ), João Pessoa, PB.

Contato com as autoras:

Curso de Psicologia, Centro Universitário de João Pessoa - UNIPÊ

Angela Elizabeth Lapa Coêlho

BR 230, Água Fria - CEP 58053-000 - João Pessoa-PB, Brasil

E-mail: coelho.angela1@gmail.com 